\title{
The Connotation and Characteristics of Educational Modernization in the Information Age
}

\author{
Xin Cao \\ Shihezi University, Shihezi, Xinjiang 832000, China \\ 569230019@qq.com
}

Keywords: Information age; Education; Modernization; Connotation and Characteristics

\begin{abstract}
The education in information age is the selective use of information means, effective access to information and the basic ability to innovate information. To cultivate students' interest in learning and applying information technology and to improve their ability to adapt to future social competition and development, so as to improve learning efficiency. This paper mainly discusses the content of education modernization in the information age, and mainly introduces the education problem under the information age, which analyzes the connotation and characteristics of educational modernization in the information age, and expounds the influence of information technology on education.
\end{abstract}

\section{Introduction}

In the information age of rapid development, information has increasingly become the most active and decisive factor in various fields of society. The information age has injected new vitality into education, and has made a profound impact on education. At the same time, higher requirements have been put forward. In particular, the rapid development of information technology has changed everything in the world, making the educational system gradually challenged by hundreds of years and thousands of years [1-3]. Facing the unprecedented information technology revolution, the profound change of the traditional education system has become a historical necessity. This paper mainly discusses the content of educational modernization in the information age, which mainly introduces the education problems in the information age and it analyzes the connotation and characteristics of the education modernization in the information age.

\section{Education in the information age}

With the development of information technology and its application in education, education will change fundamentally from content, form, method and organization. This change is not accomplished overnight, and needs to go through many intermediate processes. People will start a computer as a unique object, like physics, chemistry, dedicated to the creation of a computer course; secondly, the traditional teaching requires that the computer can assist the school, as a teaching demonstration or individual teaching; then the requirements on computer based curriculum reform, and the curriculum is obviously different in the book, chalk and blackboard, slide projector, TV and video as well as other traditional teaching media based curriculum; finally a comprehensive reform of the whole teaching system, the teaching objectives, contents, methods and forms of even the schools are undergoing fundamental changes in structure $[4,5]$. From this evolution process, we can see that the integration of computer and education is more and more deep, and the impact on education is more and more big.

In the information age of rapid development, information has increasingly become the most active and decisive factor in various fields of society. It has become the inevitable trend of education reform to carry out information education and cultivate learners' information consciousness and information ability. Information education: broadly speaking, information education is an educational activity in 
order to cultivate the information processing ability of the members of society. In a narrow sense, information education is an educational activity to train students' ability of information processing. [6] "Information processing ability" refers to the basic ability of learners to make use of information tools (means) in the activities of information society, and effectively acquire information, use information and innovate information. The content of information education includes information technology, information application and so on. Figure 1 is an analysis of the characteristics of educational informatization technology.

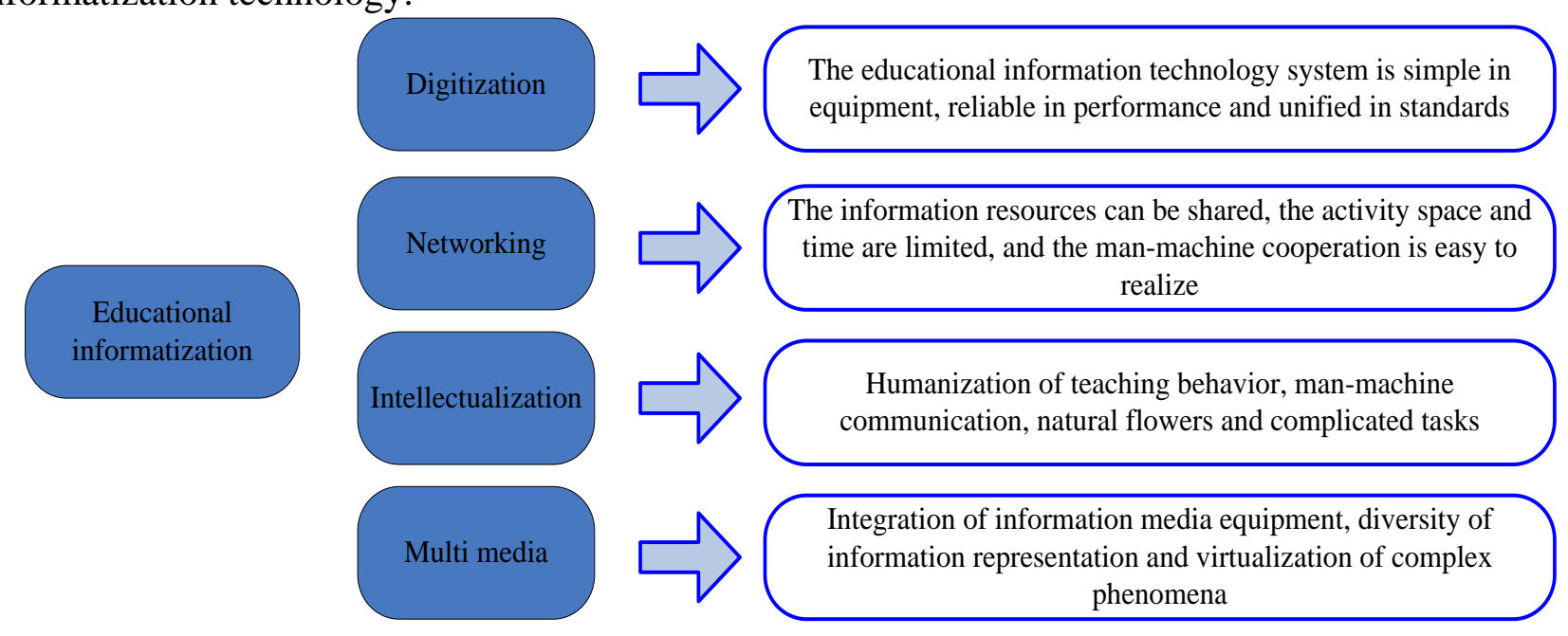

Figure 1. Analysis of technical characteristics of educational informatization

The development of information education is conducive to the realization of learners' active learning, and is conducive to the implementation of quality education. In the traditional education model, teachers are not only the organizers of teaching, but also the disseminators of learning information. Through the development of information education, learners can use information tools (means) to actively acquire relevant learning information. In the process of learning, learners can not only master the knowledge and skills, but also learn how to learn. Therefore, it is conducive to the implementation of quality education on the cultivation of students' innovative spirit and creative ability.

\section{The connotation and characteristics of educational modernization in the information age}

Connotation. Chinese scholars have done a lot of research on the connotation of educational modernization in the information age, and a lot of researches have been done by Chinese scholars. As for education modernization, some scholars define it from the content point of view, and some of them define it from the perspective of function or form change [7, 8]. A comparatively comprehensive viewpoint holds that the connotation of the modernization of education and education in the information age is mainly the connotation of the concept of modernization of education:

(1)Education modernization is not a form of education, but a certain level of education, which refers to the higher standards reached by the development of education. It is the level state of education with the social, economic, scientific and technological as well as the corresponding national psychology of a country or region, which has the advanced characteristics of modern society.

(2)Just as modernization is not a fixed goal, it is a dynamic process of change. Education modernization is also a dynamic process of development as an integral part of modernization. On the whole, it is a conscious and purposeful activity of human beings.

(3)Educational modernization is the transformation from the traditional education form that adapts to the traditional agricultural society to the modern education form that adapts to the industrial society. Its essence is to break through the shackles of tradition and establish a transcendent educational mechanism. The process of educational modernization is the process of criticism, inheritance and development of traditional education. 
(4)Education modernization is not an isolated and narrow number increase phenomenon, but a general integral transformation, and an overall transformation movement of education.

(5)The basic symbol of modernization is man's modernization, which is the comprehensive, free and full development of human beings.

Education is the foundation of human being. The modernization of human beings and the cultivation of modern people cannot be separated from modern education. Education is an important factor to determine a person's modernity. The degree of education directly determines the level of individual modernization and the transformation of modern quality. Therefore, education modernization is the only way to realize human modernization. The core of education modernization is to realize people's modernization.

Characteristics. Scholars have the following views on the characteristics of educational modernization. The modernization of education has the following characteristics: general education legalization and democratization of education, the national education, the integrity of the structure, the scientific educational theory and method of differentiation, education technology, lifelong education, education internationalization and globalization. Professor Lu Xiaozhong of South China Normal University believes that education modernization has two characteristics: standardization and characterization [9]. Standardization refers to a kind of education modernization which is universal, common and unified from the regional sense. The characteristic refers to the educational modernization which is based on a certain region, and is consistent with and adapted to its society, culture and environment.

Some scholars integrated the various views, characteristics of the modernization of education are the following: universal education, lifelong education, open education, the combination of education and labor education must be shaping the modern quality education, scientific education, legal system, education diversification [10]. According to the educational reality of contemporary China, Professor Gu Mingyuan thinks that education modernization can be measured by nine indicators, as shown in figure 2.

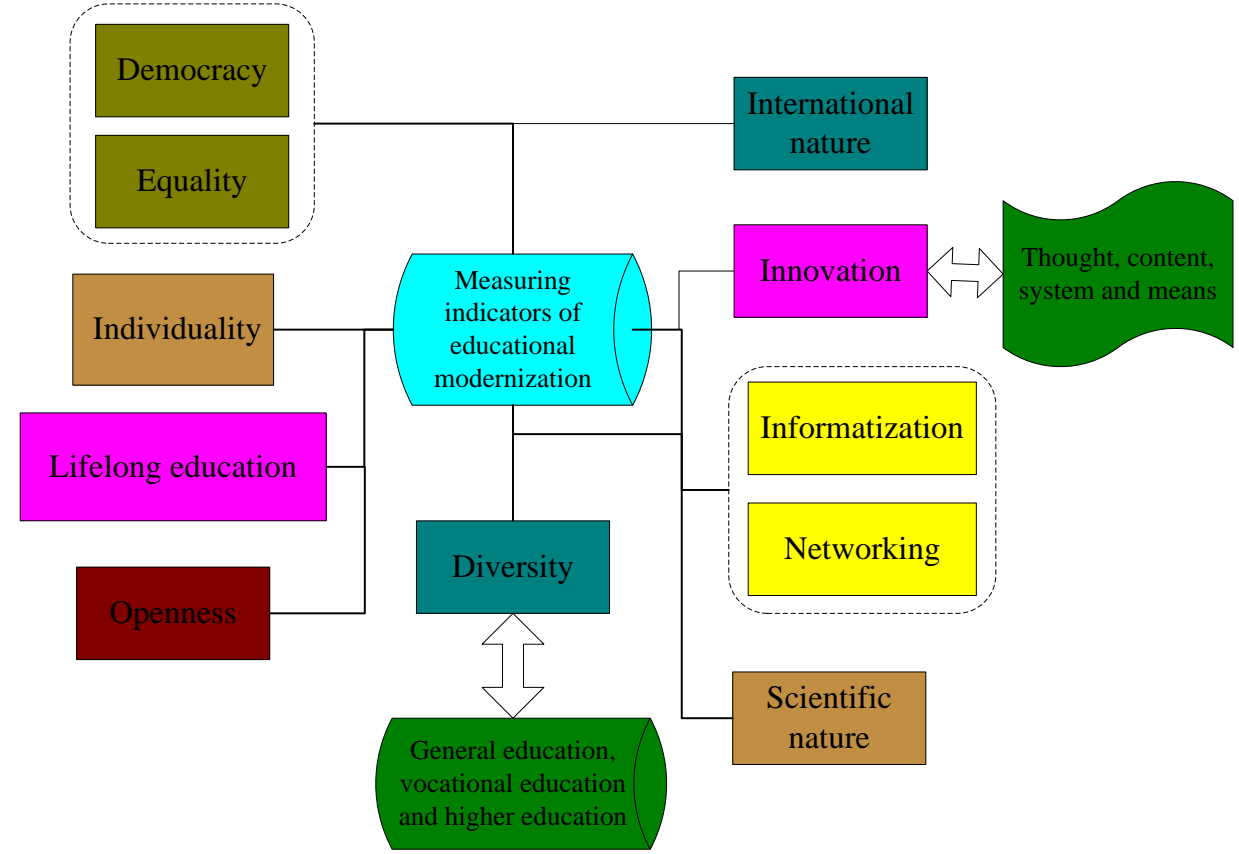

Figure 2. Measuring indicators of educational modernization

(1) Democracy and equality of education.

(2) The individuality of education.

(3) Lifelong education.

(4) The diversity of education.

(5) The openness of education.

(6) The international nature of education.

(7) The innovation of education. 
(8) The informatization and networking of education.

(9) The scientific nature of education.

These characteristics have also been recognized by most experts and scholars, so we have reason to think that the characteristics of special education modernization must be based on the specialization and specialization of the characteristics. We can also examine the special education in the middle developed countries.

\section{The influence of information technology on education}

With the continuous development of information society, traditional education is becoming more and more unable to meet the requirements of social development. The requirements of information society for education and the impact of information technology on education have revolutionized the traditional education, and the urgent task of this reform is to reform the structure, content and mode of education. First of all, we should break the traditional educational thought and set up the modern educational thought and idea [11]. The modern educational thought mainly includes: modern education view, modern teaching view, modern student view, modern teaching material view, modern school view and modern talented person view. Traditional teaching emphasizes too much on the leading role of teachers and the imparting of book knowledge, but neglects the cultivation of students' main body function and ability. It thinks that only one function of teaching is to impart book knowledge. The modern teaching view believes that teaching has many functions, it not only impart knowledge, but also develop a variety of abilities, such as learning ability and information ability, but also to cultivate moral character. In order to achieve the new educational goal, educational content must also be changed accordingly. The general trend is: the difficulty of teaching materials increases, pay attention to the basic theory, emphasize the internal connection of knowledge.

In the curriculum design focus on academic structure, teaching content and fine, focusing on the students to master the basic principles to develop students' cognitive ability. The content of education should also be combined with production practice, and focus on cultivating students' ability to solve practical problems. Information education is no longer limited to the traditional class teaching system. This kind of single teaching organization form, but the combination of traditional education, individualized education and distance education, the coexistence of various forms of running school, the coexistence of different types and levels of schools, and the integration of various functions of education. Focusing on individual education and innovative independent learning, so that educators have great freedom to choose and develop space to make it more responsive to the requirements of social development, reflecting the characteristics of the information age.

\section{Summary}

In a word, information technology provides a lot of ways for the realization of contemporary education theory, and brings great changes to the contemporary education. But at the same time, we should not completely deny the advantages of traditional classroom teaching. The school should give full play to its unique cultural and emotional atmosphere, optimize the design of teaching, seek the best combination of classroom teaching, high quality and efficient cultivation can adapt to the requirements of the times, for the new talent need of twenty-first Century.

\section{References}

[1] Yin D, University S N. Theory Basis, Connotation Features and Structure Building of Education Governance Modernization[J]. Chongqing Higher Education Research, 2015.

[2] Yin D, Xu F, University S N, et al. Higher Education Modernization: Essence, Modern Characteristics and Implementation[J]. Shandong Higher Education, 2015.

[3] Fan K S. Promoting Measures and Comprehensive Evaluation of the Agricultural Modernization in Henan Province[J]. Hubei Agricultural Sciences, 2015. 
[4] Wang C J, Yu-Hai H E. On the Connotation, Characteristics and Implementation Strategies of Higher School Educational Plan Management[J]. Theory \& Practice of Education, 2016.

[5] Chen K, University S. The Connotation、Characteristics and Cultivation Conditions of Students' Core Accomplishment in the Basic Education Stage[J]. Education \& Teaching Research, 2017.

[6] Yang H. “Triple-Innovation” Talent in the Age of "Internet plus”: Connotation, Characteristics and Cultivative Path_—A Case Study of the Major of Digital Media Art[J]. Theory \& Practice of Education, 2017.

[7] Liu X. The Connotation Definition and Characteristics Analysis of Emerging Information Consumption[J]. Information Studies Theory \& Application, 2016.

[8] Tong S. On the Connotation and Characteristics of "Internet plus Teaching" in the Colleges and Universities[J]. Chongqing Higher Education Research, 2017.

[9] Li J. Connotation and Realistic Consideration of National Governance Modernization[J]. Chongqing Social Sciences, 2017.

[10] Yang Q. Modernization of Regional Education Governance System: Connotation and Principals and Path[J]. Education Research Monthly, 2015.

[11]Yang K C, Yi X U. On the Basic Features of Modern Education and the Deep Connotation of Educational Informatization[J]. e-Education Research, 2016. 